\title{
An atypical case of post-varicella stroke in a child presenting with hemichorea followed by late-onset inflammatory focal cerebral arteriopathy
}

\begin{abstract}
Marta Bertamino $^{1 \#}$, Sara Signa ${ }^{2,3 \#}$, Giulia Vagelli ${ }^{2}$, Roberta Caorsi ${ }^{3}$, Alice Zanetti ${ }^{1}$, Stefano Volpi ${ }^{2,3}$, Giuseppe Losurdo ${ }^{4}$, Giulia Amico ${ }^{2,5}$, Icilio Dodi ${ }^{6}$, Giulia Prato ${ }^{7}$, Anna Bruna Ronchetti ${ }^{1}$, Maja Di Rocco ${ }^{8}$, Maria Nagel ${ }^{9}$, Mariasavina Severino ${ }^{10}$

${ }^{1}$ Rehabilitation Unit, IRCCS Istituto Giannina Gaslini, Genoa, Italy; ${ }^{2}$ Department of Neuroscience, Ophthalmology, Genetics and Maternal Infantile Sciences (DINOGMI), University of Genoa, Genoa, Italy; ${ }^{3}$ Autoinflammatory Diseases and Immunodeficiencies Center, IRCCS Istituto Gianina Gaslini, Genoa, Italy; ${ }^{4}$ Infectious Diseases Unit, IRCCS Istituto Gianina Gaslini, Genoa, Italy; ${ }^{5}$ Laboratory of Genetic and Genomics of Rare Disease, IRCCS Istituto Giannina Gaslini, Genoa, Italy; ${ }^{6}$ Emergency Unit, Pietro Barilla Children Hospital, Parma, Italy; ${ }^{7}$ Child Neuropsychiatry Unit, IRCCS Istituto Gianina Gaslini, Genoa, Italy; ${ }^{8}$ Rare Diseases Unit, IRCCS Istituto Giannina Gaslini, Genoa, Italy; ${ }^{9}$ Department of Neurology, University of Colorado School of Medicine, Aurora, CO, USA; ${ }^{10}$ Neuroradiology Unit, IRCCS Istituto Giannina Gaslini, Genoa, Italy
\end{abstract}

\#These authors contributed equally to this work.

Correspondence to: Marta Bertamino, MD, PhD. Largo Gerolamo Gaslini 5; 16147 Genoa, Italy. Email: martabertamino@gaslini.org.

Submitted May 01, 2020. Accepted for publication Aug 19, 2020.

doi: 10.21037/qims-20-628

View this article at: http://dx.doi.org/10.21037/qims-20-628

\section{Introduction}

Post-varicella arterial ischemic stroke (AIS) is a rare but serious complication of varicella zoster virus (VZV) infection, with an estimated incidence of $1 / 15,000$ children per year, and high risk of lifelong disability and increased mortality (1). Both in children and adults, the clinical diagnosis is based on neurological symptoms and signs due to AIS associated with a history of chickenpox or herpes zoster infection during the previous year, once other major causes for AIS are excluded $(2-4)$. Of note, this diagnosis is often challenging since previous VZV rash may be absent in $30 \%$ of patients $(5,6)$. Moreover, VZV DNA in cerebrospinal fluid (CSF) is positive in only $30 \%$ of subjects with VZV stroke, underlying that a negative PCR result does not exclude this diagnosis (5). The detection of anti-VZV IgG antibody in the CSF is the most sensitive diagnostic test, particularly when combined with demonstration of intrathecal synthesis (5-7). Qualitatively, the serum/CSF ratio of anti-VZV IgG antibody is compared with the serum/CSF ratio of albumin and total $\mathrm{IgG}$, with a reduction of the former compared with the latter representing a positive result $(8,9)$. A more quantitative assessment of intrathecal synthesis, the antibody index, has been described by Reiber and Lange: (CSF VZV IgG/serum VZV IgG)/(CSF total IgG or albumin/serum total IgG or albumin). An antibody index $\geq 1.5$ is considered as positive (8).

The underlying mechanism of VZV-associated AIS is not entirely clarified. Viral markers have been identified in patients' CSF as well as viral DNA, antigens and particles in the wall of affected arteries (7). These findings support the hypothesis of a direct VZV arterial infection associated with variable indirect inflammatory responses (6), after transaxonal viral migration from the cranial nerve ganglia to the cerebral arterial walls (2). Indeed, inflammatory focal cerebral arteriopathy is the most common cerebrovascular manifestation attributed to VZV (10), classically involving the proximal middle cerebral artery (MCA) and/or other medium-sized vessels such as the terminal internal carotid

^ ORCID: 0000-0002-8096-7806. 
artery and proximal anterior cerebral artery, with typical focal irregular narrowing and banding of the affected vessel. Multifocal small vessel vasculopathy has also been attributed to VZV infection in both immunocompetent and immunocompromised hosts (11). This vasculopathy has usually a monophasic course with possible progression within the first 6 months, followed by spontaneous regression, improvement or stabilization $(2,3,11,12)$.

Despite most of the cases present within 12 months following the primary VZV infection, a longer latency has been occasionally described (13). We report acute hemichorea as unusual presentation of a thalamic stroke in a child, seven months after a VZV infection, followed by a late-onset asymptomatic post-VZV angiopathy, two years after the VZV infection, successfully treated with steroids and acyclovir.

\section{Case presentation}

A 6-years-old girl presented with sudden onset of right hemichorea seven months after VZV infection (chickenpox). Mild difficulties in drawing and riding the bike were reported in the previous days, while there was no history of recent head trauma, headaches or even minor infections. Birth, family, and social histories were unremarkable, except for the presence of prothrombin heterozygous mutation G20210A (factor II) in two maternal cousins and one aunt. The patient was only vaccinated with inactivated vaccines, since parents had refused the recommended vaccinations with attenuated virus vaccines. Neurological examination revealed repetitive, involuntary, irregular, purposeless, and non-rhythmic movements of the right upper and inferior limbs. Brain computed tomography (CT) scan showed a focal hypodensity in the left thalamus (Figure 1A). An urgent brain magnetic resonance (MR) and MR angiography (MRA) were performed on a $1.5 \mathrm{~T}$ scanner (Siemens Avanto, Erlangen, Germany), revealing an early subacute ischemic infarct in the superior mesial portion of the thalamus, in the posterior cerebral artery territory, without signs of focal cerebral arteriopathy on MRA (Figure 1B,C,D,E). The patient underwent an extensive screening for plasmatic thrombophilia (plasma levels of protein C, protein S, antithrombin, Lupus Anticoagulant, and antiphospholipid antibodies), autoimmune conditions (plasmatic immunoglobulins, complement, anti-nuclear antibodies) and infections (serology for Cytomegalovirus, Herpes Simplex virus, Parvovirus B19, Epstein Barr virus and VZV). All tests turned out to be negative, except for positive plasmatic EBV and VZV IgG (Delta Biologicals ELISA kit), consistent with previous infection. A throat swab revealed a group A beta-hemolytic streptococcus. Genetic test for molecular thrombophilia showed a heterozygous prothrombin mutation G20210A, whereas no mutations of the Factor V Leiden were present. Cardiological evaluation, ECG and transthoracic contrast echocardiography were normal. Antiplatelet therapy with a $5 \mathrm{mg} / \mathrm{kg} /$ day dose of acetylsalicylic acid was started, with complete resolution of neurological symptoms.

The patient was referred to our Institute 4 months later for a second opinion. The neurological examination was normal. Brain MRI performed on a 3T MR scanner (Ingenia CX, Philips, Best, The Netherlands) using a 32-channel head array coil showed chronic evolution of the thalamic ischemic lesion with normal MRA (Figure 2). Considering her clinical history, according to the diagnostic criteria proposed by Lanthier (3), we suspected a post-varicella AIS and we recommended therapy with acetylsalicylic acid for 2 years. One year later, a follow-up brain MRI and MR angiography, performed with the same $3 \mathrm{~T}$ MR scanner when the patient was completely asymptomatic, revealed a focal stenosis at the origin of one sylvian branch of the left MCA with vessel wall contrast enhancement and slightly reduced distal flow signal (Figure $3 A, B, C$ ). No new ischemic lesions nor other arterial stenosis were identified. The neurological examination and 20-minute standard interictal EEG, performed with digital 10-20 International System (EBNeuro, Galileo System, EB Neuro S.p.A Florence, Italy) were normal. The neurocognitive evaluation showed no impairment on visual attention and executive functions (working memory, inhibition and cognitive flexibility). Her performances were within or slightly above the average range at Numerical Stroop (14), Inhibition (15), Trail Making Test (16) and Cancellation (17). Working memory capacity, assessed with backward digit span (18) and an experimental dual-task word span test (19), was above the average range. The non-verbal cognitive functioning was measured with the Coloured Progressive Matrices (20) and it was above the average range for age (score: $99^{\circ}$ percentile; IQ class: range, 125-135). At the parent-report questionnaires $(14,21)$, used to assess socio-emotional and behavioral problems, she showed no significant impairment.

CSF examination revealed no pleocytosis, negative VZV-PCR but intrathecal VZV antibodies synthesis with an elevated antibody index. The diagnosis of late recurrent post varicella Arteriopathy (PVA) was therefore made and steroidal treatment with iv methylprednisolone 

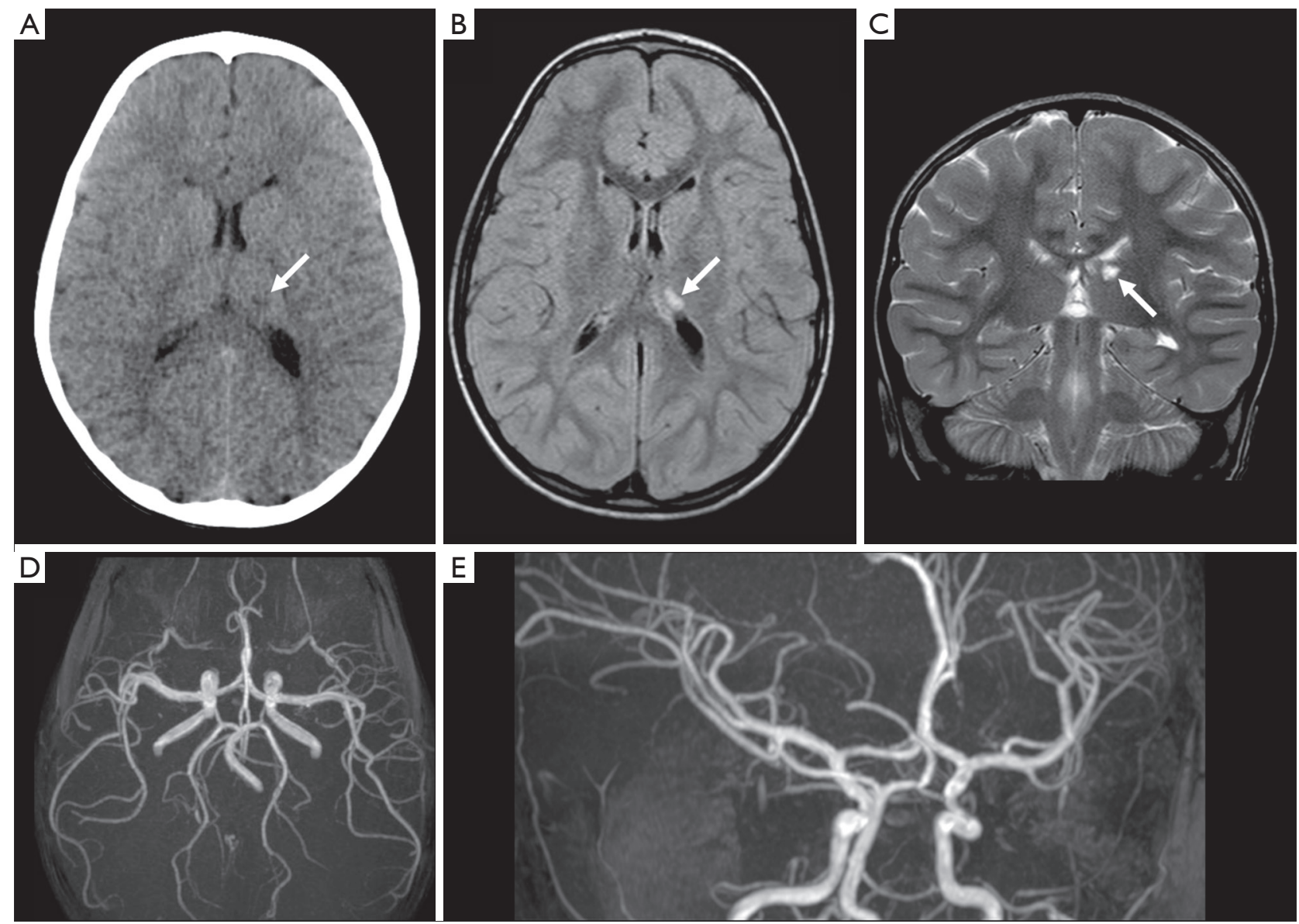

Figure 1 Head CT, brain MRI and MR angiography (MRA) at clinical onset. (A) Axial head CT image reveals a small hypodense lesion in the left medial thalamus (arrow); (B) Corresponding axial FLAIR image and (C) coronal T2-weighted image show a hyperintense lesion consistent with an early subacute ischemic infarct in the territory of perforating arteries from the posterior cerebral artery (arrows); (D,E) 3D TOF MRA images reveal absence of focal cerebral arteriopathy. In particular, there is no visible stenosis at the level of the left posterior cerebral artery and the left middle cerebral artery (MCA) is normal.

$2 \mathrm{mg} / \mathrm{kg} /$ day, later switched to oral prednisone, was started as well as antiviral therapy with iv acyclovir $10 \mathrm{mg} / \mathrm{kg} \times$ $3 /$ day. The patient had a negative personal medical history for frequent and/or severe infections or other signs of immune deficiency symptoms. Moreover, laboratory testing did not show immunological changes. Pathogenetic variants associated with susceptibility to brain VZV infections in the RNA Polymerase III subunit C (POLR3C), A (POLR3A) and $\mathrm{F}(P O L R 3 F)$ genes were ruled out (22-25) via targeted Next Generation Sequencing panel and Sanger Sequencing. Finally, a NGS panel including 15 genes was performed to exclude the more frequent monogenetic causes of stroke in children (26,27). In particular, considered the involvement of posterior circulation at clinical onset, pathogenic variants in the $A D A 2$ gene, encoding the adenosine deaminase 2 and responsible for a multisystem disease associated with early onset recurrent lacunar strokes, were excluded (28).

Follow-up brain MRI and MRA after one month showed reduction of the vessel wall contrast enhancement and slightly improved flow signal at the level of the MCA branch (Figure 3D,E,F). The steroid therapy was thus gradually tapered until suspension after 6 months. Oral Acyclovir (20 $\mathrm{mg} / \mathrm{kg} \times 3 /$ day) was withdrawn after steroids, in order to prevent viral reactivation due to the immune suppression.

After 6 months, a new brain MRI and MRA revealed resolution of vessel wall contrast enhancement but persistent mild stenosis at the origin of the left MCA branch, consistent with fibrotic evolution of the inflammatory process, resulting 

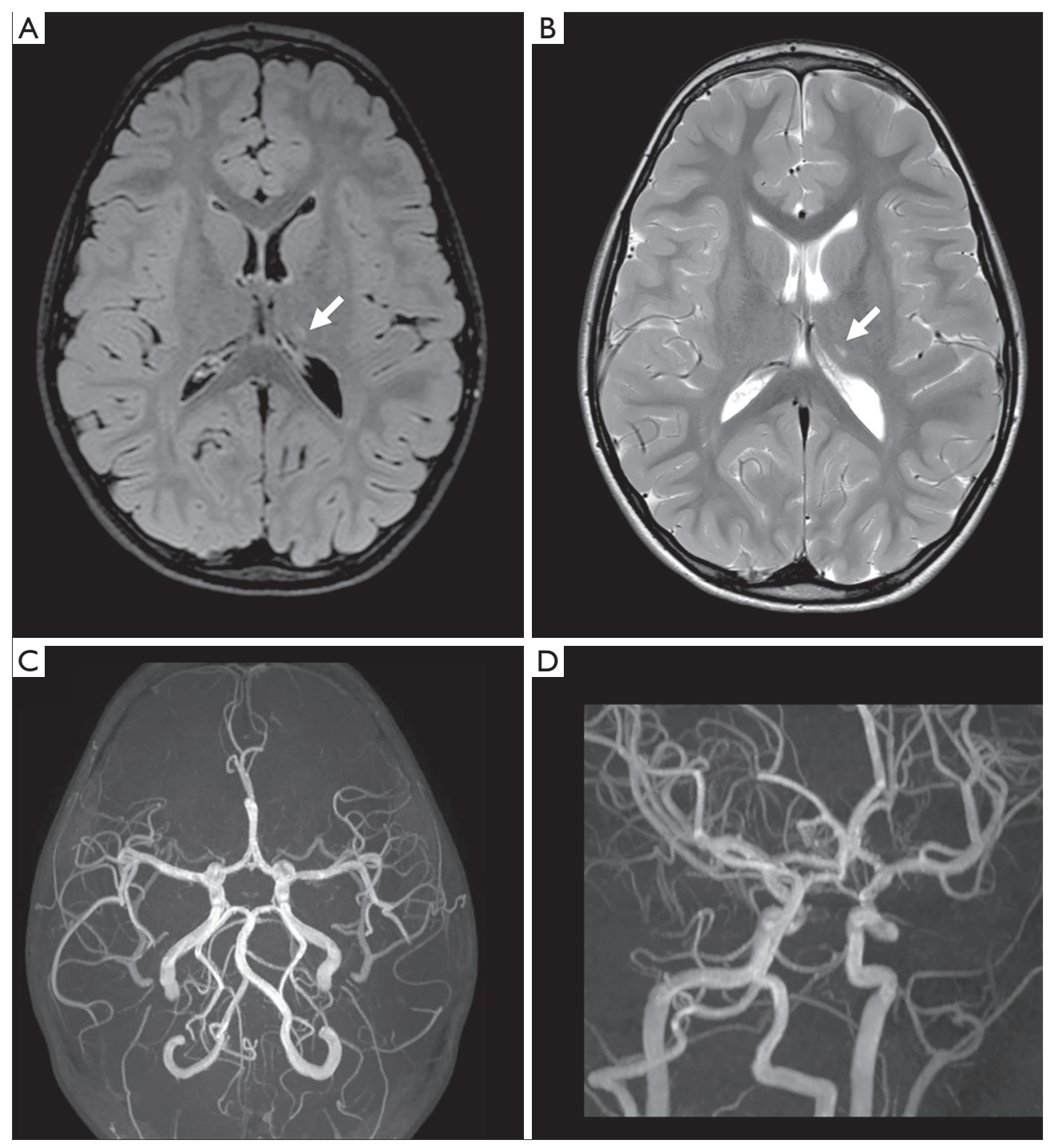

Figure 2 Follow-up brain MRI and MRA performed 4 months after clinical onset. (A) axial FLAIR and (B) T2-weighted images demonstrate chronic evolution of the thalamic arterial ischemic infarct, with a small residual gliotic lesion (arrows); (C,D) 3D TOF MRA images demonstrate normal findings.

in a persistent focal cerebral arteriopathy. At last followup, one year later, the patient was asymptomatic and she underwent the same neuropsychological evaluation, showing no impairment. Her performance further improved on working memory tasks.

\section{Discussion}

We reported an atypical case of post-varicella thalamic stroke in a 6 years-old girl presenting with hemichorea, followed by late-onset inflammatory VZV-related focal cerebral arteriopathy detected by high-resolution vessel wall MRI and confirmed on cerebrospinal fluid analysis by VZVspecific antibody index.

Hyperkinetic movement disorders are uncommon in acute stroke, with a prevalence of $1 \%$ and an estimated incidence of $0.08 \%$ per year in adults (29). The anatomic basis of hemichorea is not related to a single specific topographical location and can be due to any lesions involving the cortico-striato-pallido-thalamo-cortical feedback loop, including the caudate nucleus, putamen, thalamus, subthalamus, and subcortical white matter (30). 

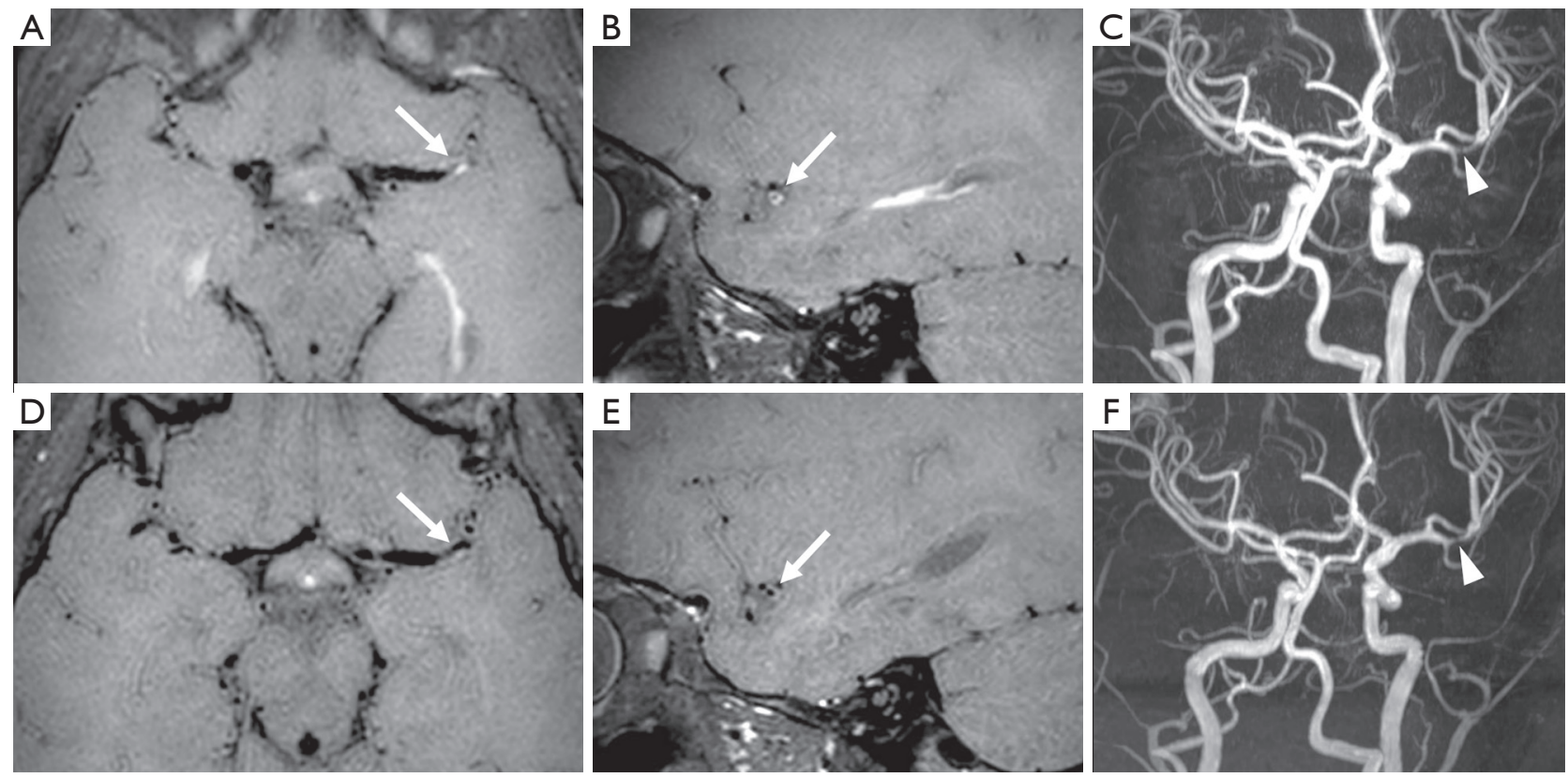

Figure 3 Brain MRI and MRA performed 16 months after clinical onset (A,B,C) and one month later (D,E,F). (A) Axial and (B) sagittal black-blood vessel wall images reveal concentric parietal contrast enhancement at the origin of one sylvian branch of the left middle cerebral artery (arrows), in keeping with segmental arterial wall inflammation. (C) Coronal oblique 3D MRA view demonstrates a focal stenosis of the involved arterial segment (arrowhead). (D) Corresponding axial and (E) sagittal black-blood vessel wall images, performed one month later, show marked reduction of the vessel wall contrast enhancement (arrows). (F) Coronal oblique 3D MRA views reveal persistent focal stenosis of the middle cerebral artery branch (arrowhead).

Of note, acute-onset chorea in the pediatric population is most commonly associated with Sydenham chorea, which is a manifestation of acute rheumatic fever, while other infectious, metabolic, cardiac and toxic causes are less frequent (31). In the present patient, the short latency between the clinical onset and streptococcus detected on a throat swab in association with clear laterality of the extrapyramidal movements were not typical of this condition. Moreover, the demonstration of an acute left thalamic ischemic stroke on brain MRI was consistent with a vascular origin of this extrapyramidal symptom.

Interestingly, in this patient we detected an inflammatory focal cerebral arteriopathy involving the MCA, 24 months after the VZV infection and 18 months after a lacunar thalamic infarct in the posterior cerebral artery territory without visible arteriopathy. According to the literature, the risk of stroke is highest in the first six months and is considered to significantly decrease 12 months after VZV infection. However, there is increasing evidence of virologically-confirmed PVA and post-VZV stroke after a longer interval from the primary infection (13). In particular, anecdotal occurrence of PVA has been described up to 4 years after the infection $(5,13,32-34)$. In the present patient, the diagnosis of inflammatory focal cerebral arteriopathy was made with high resolution vessel wall MR imaging, on a routine follow-up, when the patient was completely asymptomatic. Even if angiography remains the gold standard for the diagnosis of cerebral arterial stenosis, it cannot provide information regarding the arterial wall. The sensitivity of standard MR angiography for PVA does not exceed $70 \%$, with specificity being even lower. Therefore, we cannot exclude the presence of a PVA involving the posterior cerebral and/or thalamoperforating arteries at the time of clinical onset. Of note, although less frequently, the posterior circulation may also be affected by PVA (35). Recently, the advent of high-resolution vessel wall MRI has allowed the depiction of vessel wall contrast enhancement in patients with central nervous system arteritis, indicating vessel wall inflammation, also due to VZV (36,37). As in the present case, cerebral vasculitis appears with a concentric, diffuse, and smooth pattern of enhancement as opposed to atherosclerotic lesions that are extremely infrequent in children and present with eccentric, focal, and irregular enhancement. Recommendations 
regarding the timing of neuroradiological follow-up in patients with VZV-related stroke are still lacking. The present case suggests that neuroradiological follow-up with high resolution vessel wall imaging might be useful for at least two years after VZV infection, even in asymptomatic patients or when no residual focal cerebral arteriopathy is demonstrated at AIS onset. In addition, the more recent literature highlights the importance of performing the CSF analysis in all patients with pediatric stroke of undefined origin $(5,9)$. Indeed, the diagnosis of PVA relies on virologic confirmation that detects VZV DNA, anti-VZV IgG antibody, or both in the CSF. In particular, the detection of anti-VZV IgG antibodies in the CSF has a high sensitivity and specificity, and it is therefore a more useful diagnostic test than detection of amplifiable VZV DNA (9).

The role of targeted antiviral and/or anti-inflammatory steroid therapies in post-VZV AIS is still debated. Indeed, there are only few papers reporting the outcome of patients treated with antiviral and steroid, and prospective randomized studies are still missing $(4,34,38-43)$. Based upon Level 2 class of evidence (systemic review of cohort studies and individual cohort studies) (6), antiviral therapy with iv acyclovir is proposed in VZV-angiopathy for 14-21 days, which may be prolonged in immunosuppressed/immunocompromised patients in whom recurrence is common (7). In addition, steroidal treatment is commonly associated to reduce the inflammation related to the VZV-related granulomatous arteritis, even if strong evidences and recommendations about doses and duration are still lacking $(2,38)$.

Of note, when the lumbar puncture was performed in our patient, the VZV-PCR was negative, but VZVspecific antibody index in the CSF was highly positive, substantiating an intrathecal antibodies synthesis. Thanks to the CSF confirmation, we could define the appearance of the inflammatory intracranial stenosis in a previously normal vascular district, as a late recurrence of PVA. We thus decided to implement the 2-year antiplatelet therapy (38), adding i.v. steroid (metilprednisolone $2 \mathrm{mg} / \mathrm{kg} /$ day) therapy for 5 days and i.v. acyclovir $(10 \mathrm{mg} / \mathrm{kg} /$ three times a day) for 14 days. Due to the lack of standardized therapeutic protocols in PVA, we monitored the results of the treatment using high resolution vessel wall MRI, tapering and then stopping the steroid therapy and prophylactic oral acyclovir after resolution of vessel wall contrast enhancement. Despite high-resolution vessel wall imaging has already been used to track the treatment response in PVA (44), its potential role as a marker of treatment response in CNS vasculitis remains to be explored, due to heterogeneity of disease activity and lack of longitudinal studies evaluating the course of resolution of vessel wall enhancement with and without treatment, also considering the typical selflimiting course of PVA.

We speculate that the fact that the antiviral therapy was not started during the first AIS episode might have increased the risk of recurrence (2). Of note, this girl had no other stroke risk factors, except for the presence of prothrombin heterozygotes mutation G20210A, detected also in other asymptomatic family members, that might have been a contributing but not causative factor. Additionally, both immunocompetence problems and genetic predisposition for PVA and AIS in general were excluded.

Finally, it is important to notice that the present patient was only vaccinated with inactivated vaccines, since parents had refused the recommended attenuated virus vaccines. As showed by the VIPS study (45), undervaccination is a risk factor for childhood AIS, and many studies have shown the decreasing incidence of stroke due to the universal introduction of live attenuated VZV vaccine, that may be considered safe in non-immunosuppressed infants (46-49).

In summary, this case report underlies the importance to consider AIS as a possible cause of unilateral involuntary movements also in children, and demonstrates how lumbar puncture with measurements of both VZV DNA copies and specific intrathecal antibodies synthesis can be crucial to reach the final diagnosis. Moreover, we provide further evidence of possible late recurrence of VZV-arteriopathy, with potential important consequences for clinical but also neuroimaging follow-up in subjects with post-VZV AIS. Finally, despite large pediatric studies are still awaited, high resolution vessel wall MRI seems to be a promising imaging tool not only for depicting arterial wall inflammatory changes in PVA, but also to monitor the response to antiviral and anti-inflammatory treatment (50).

\section{Acknowledgments}

We would like to thank "Associazione per la Lotta all'Ictus Cerebrale" (ALICe) for the support and the patient and her family.

Funding: This work was supported by Compagnia San Paolo (Reaserch Grant to MDR; SIME 2017-0621, ROL 20573) and by funds from "Ricerca Corrente 2020" of the Italian Ministry of Health, assigned to Rehabilitation Unit of IRCCS Giannina Gaslini. 


\section{Footnote}

Conflicts of Interest: All authors have completed the ICMJE uniform disclosure form (available at http://dx.doi. org/10.21037/qims-20-628). Dr. Bertamino reports grants from Compagnia San Paolo, during the conduct of the study. All the authors declare that the research was conducted in the absence of any commercial or financial relationships that could be construed as a potential conflict of interest.

Ethics Statement: Written informed parental consent was obtained for publication of this case report.

Open Access Statement: This is an Open Access article distributed in accordance with the Creative Commons Attribution-NonCommercial-NoDerivs 4.0 International License (CC BY-NC-ND 4.0), which permits the noncommercial replication and distribution of the article with the strict proviso that no changes or edits are made and the original work is properly cited (including links to both the formal publication through the relevant DOI and the license). See: https://creativecommons.org/licenses/by-nc-nd/4.0/.

\section{References}

1. Reis AF, Pais P, Monteiro JP. Chickenpox and stroke in children: case studies and literature review. Acta Paediatr 2014;103:e176-80.

2. Amlie-Lefond C, Gilden D. Varicella Zoster Virus: A Common Cause of Stroke in Children and Adults. J Stroke Cerebrovasc Dis 2016;25:1561-9.

3. Lanthier S, Armstrong D, Domi T, DeVeber G. Postvaricella arteriopathy of childhood: Natural history of vascular stenosis. Neurology 2005;64:660-3.

4. Grose C. Stroke after varicella and zoster ophthalmicus: another indication for treatment and immunization. Pediatr Infect Dis J 2010;29:868-9.

5. Nagel MA, Cohrs RJ, Mahalingam R, Wellish MC, Forghani B, Schiller A, Safdieh JE, Kamenkovich E, Ostrow LW, Levy M, Greenberg B, Russman AN, Katzan I, Gardner CJ, Häusler M, Nau R, Saraya T, Wada H, Goto H, de Martino M, Ueno M, Brown WD, Terborg $\mathrm{C}$, Gilden DH. The varicella zoster virus vasculopathies: clinical, CSF, imaging, and virologic features. Neurology 2008;70:853-60.

6. Nagel MA, Bubak AN. Varicella Zoster Virus Vasculopathy. J Infect Dis 2018;218:S107-12.
7. Nagel MA. Varicella zoster virus vasculopathy: Clinical features and pathogenesis. J Neurovirol 2014;20:157-63.

8. Reiber H, Lange P. Quantification of virus-specific antibodies in cerebrospinal fluid and serum: Sensitive and specific detection of antibody synthesis in brain. Clin Chem 1991;37:1153-60.

9. Nagel MA, Forghani B, Mahalingam R, Wellish MC, Cohrs RJ, Russman AN, Katzan I, Lin R, Gardner CJ, Gilden DH. The value of detecting anti-VZV IgG antibody in CSF to diagnose VZV vasculopathy. Neurology 2007;68:1069-73.

10. Silverstein FS, Brunberg JA. Postvaricella basal ganglia infarction in children. AJNR Am J Neuroradiol 1995;16:449-52.

11. Gilden D, Cohrs RJ, Mahalingam R, Nagel MA. Varicella zoster virus vasculopathies: diverse clinical manifestations, laboratory features, pathogenesis, and treatment. Lancet Neurol 2009;8:731-740.

12. Braun KP, Bulder MM, Chabrier S, Kirkham FJ, Uiterwaal CS, Tardieu M, Sébire G. The course and outcome of unilateral intracranial arteriopathy in 79 children with ischaemic stroke. Brain 2009; 132:544-57.

13. Häusler MG, Ramaekers VT, Reul J, Meilicke R, Heimann G. Early and late onset manifestations of cerebral vasculitis related to varicella zoster. Neuropediatrics 1998;29:202-7.

14. Marzocchi GM, Re AM, Cornoldi C. Italian ADHD Battery. Trento: Erickson, 2010.

15. Korkman M, Kirk U, Kemp S. NEPSY-Second Edition (NEPSY-II). San Antonio, TX: Harcourt Assessment, 2007.

16. Scarpa P, Piazzini A, Pesenti G, Brovedani P, Toraldo A, Turner K, Scotti S, Dal Lago C, Perelli V, Brizzolara D, Canger R, Canevini MP, Bottini G. Italian neuropsychological instruments to assess memory, attention and frontal functions for developmental age. Neurol Sci 2006;27:381-96.

17. Wechsler D. Wechsler intelligence scale for children - Fourth edition (WISC-IV). San Antonio, TX: The Psychological Corporation, 2003.

18. Tressoldi PE, Vio C, Gugliotta M, Bisiacchi PS, Cendron M. Neuropsychological battery for evaluation of developmental age. Trento: Erickson, 2005.

19. Belacchi C, Carretti B, Cornoldi C. The role of working memory and updating inColoured Raven Matrices performance in typicallydeveloping children. Eur J Cogn Psychol 2010;22:1010-20.

20. Raven JC. Coloured Progressive Matrices. Oxford, England: Oxford Psychologists Press/San Antonio, TX: 
The Psychological Corporation. 1947.

21. Goodman R. The Strengths and Difficulties

Questionnaire: a research note. J Child Psychol Psychiatry 1997;38:581-6.

22. Ogunjimi B, Zhang S-Y, Sørensen KB, Skipper KA, Carter-Timofte, M Kerner G, Luecke S, Prabakaran T, Cai Y, Meester J, Bartholomeus E, Bolar NA, Vandeweyer G, Claes C, Sillis Y, Lorenzo L, Raffaele A. Fiorenza, Soraya Boucherit, Dielman C, Heynderickx S, Elias G, Kurotova A, Auwera AV, Verstraete L, Lagae L, Verhelst H, Jansen A, Ramet J, Suls A, Smits E, Ceulemans B, Laer LV, Wilson GP, Kreth J, Picard C, Bernuth HV, Fluss J, Chabrier S, Abel L, Mortier G, Fribourg S, Mikkelsen JG, Casanova JL, Paludan SR, Mogensen THInborn errors in RNA polymerase III underlie severe varicella zoster virus infections. J Clin Invest 2017;127:3543-56.

23. Carter-Timofte ME, Paludan SR, Mogensen TH. RNA Polymerase III as a Gatekeeper to Prevent Severe VZV Infections. Trends Mol Med 2018;24:904-15.

24. Carter-Timofte ME, Hansen AF, Christiansen M, Paludan SR, Mogensen TH. Mutations in RNA Polymerase III genes and defective DNA sensing in adults with varicellazoster virus CNS infection. Genes Immun 2019;20:214-23.

25. Carter-Timofte ME, Hansen AF, Mardahl M, Fribourg S, Rapaport F, Zhang SY, Casanova JL, Paludan SR, Christiansen M, Larsen CS, Mogensen TH. Varicellazoster virus CNS vasculitis and RNA polymerase III gene mutation in identical twins. Neurol Neuroimmunol Neuroinflamm 2018;5:e500.

26. Grossi A, Severino M, Rusmini M, Tortora D, Ramenghi L, Cama A, Rossi A, Di Rocco M, Ceccherini I, Bertamino M. Targeted re-sequencing in pediatric and perinatal stroke. Eur J Med Genet 2020;63:104030.

27. Munot P, Crow YJ, Ganesan V. Paediatric stroke: genetic insights into disease mechanisms and treatment targets. Lancet Neurol 2011;10:264-74.

28. Caorsi R, Penco F, Grossi A, Insalaco A, Omenetti A, Alessio M, Conti G, Marchetti F, Picco P, Tommasini A, Martino S, Malattia C, Gallizi R, Podda RA, Salis A, Falcini F, Schena F, Garbarino F, Morreale A, Pardeo M, Ventrici C, Passarelli C, Zhou Q, Severino M, Gandolfo C, Damonte G, Martini A, Ravelli A, Aksentijevich I, Ceccherini I, Gattorno M. ADA2 deficiency (DADA2) as an unrecognised cause of early onset polyarteritis nodosa and stroke: a multicentre national study. Ann Rheum Dis 2017;76:1648-56.

29. Suri R, Rodriguez-Porcel F, Donohue K, Jesse E, Lovera L, Dwivedi AK, Espay AJ. Post-stroke Movement Disorders:
The Clinical, Neuroanatomic, and Demographic Portrait of 284 Published Cases. J Stroke Cerebrovasc Dis 2018;27:2388-97.

30. Ghika-Schmid F, Ghika J, Regli F, Bogousslavsky J. Hyperkinetic movement disorders during and after acute stroke: The Lausanne Stroke Registry. J Neurol Sci 1997;146:109-16.

31. de Gusmao CM, Waugh JL. Inherited and Acquired Choreas. Semin Pediatr Neurol 2018;25:42-53.

32. Miravet E, Danchaivijitr N, Basu H, Saunders DE, Ganesan V. Clinical and radiological features of childhood cerebral infarction following varicella zoster virus infection. Dev Med Child Neurol 2007;49:417-22.

33. Ganesan V, Kirkham FJ. Mechanisms of ischaemic stroke after chickenpox. Arch Dis Child. 1997;76:522-5.

34. Ciccone S, Faggioli R, Calzolari F, Sartori S, Calderone M, Borgna-Pignatti C. Stroke after varicella-zoster infection: Report of a case and review of the literature. Pediatr Infect Dis J 2010;29:864-7.

35. Hoshino T, Toi S, Toda K, Uchiyama Y, Yoshizawa H, Iijima M, Shimizu Y, Kitagawa K. Ischemic Stroke due to Virologically-Confirmed Varicella Zoster Virus Vasculopathy: A Case Series. J Stroke Cerebrovasc Dis 2019;28:338-43.

36. Waters MJ, Kleinig T. Black-blood magnetic resonance imaging demonstrates varicella zoster vasculitis. Intern Med J 2018;48:1408-10.

37. Tsivgoulis G, Lachanis S, Magoufis G, Safouris A, Kargiotis O, Stamboulis E. High-resolution vessel wall magnetic resonance imaging in varicella-zoster virus vasculitis. J Stroke Cerebrovasc Dis 2016;25:e74-6.

38. Ferriero DM, Fullerton HJ, Bernard TJ, Billinghurst L, Daniels SR, DeBaun MR, deVeber G, Ichord RN, Jordan LC, Massicotte P, Meldau J, Roach ES, Smith ER. Management of Stroke in Neonates and Children: A Scientific Statement From the American Heart Association/American Stroke Association. Stroke 2019;50:e51-96.

39. Monteventi O, Chabrier S, Fluss J. Prise en charge diagnostique et thérapeutique actuelle des accidents vasculaires cérébraux post-varicelleux chez l'enfant: Revue de la littérature. Arch Pediatr 2013;20:883-9.

40. Bartolini L, Gentilomo C, Sartori S, Calderone M, Simioni P, Laverda AM. Varicella and stroke in children: Good outcome without steroids. Clin Appl Thromb Hemost 2011;17:E127-30.

41. Science M, Macgregor D, Richardson SE, Mahant S, Tran D, Bitnun A. Central nervous system complications of 
varicella-zoster virus. J Pediatr 2014;165:779-85.

42. Dunkhase-Heinl U, Stausbøl-Grøn B, Christensen J, Ostergaard JR. Post-varicella angiopathy: A series of 4 patients with focus on virologic and neuroimaging findings. Pediatr Neurol 2014;50:581-5.

43. Helmuth IG, Mølbak K, Uldall PV, Poulsen A. Postvaricella Arterial Ischemic Stroke in Denmark 2010 to 2016. Pediatr Neurol 2018;80:42-50.

44. Mossa-Basha M, Alexander M, Gaddikeri S, Yuan C, Gandhi D. Vessel wall imaging for intracranial vascular disease evaluation. J Neurointerv Surg 2016;8:1154-9.

45. Elkind MS, Hills NK, Glaser CA, Lo WD, AmlieLefond C, Dlamini N, Kneen R, Hod EA, Wintermark M, deVeber GA, Fullerton HJ; VIPS Investigators*. Herpesvirus Infections and Childhood Arterial Ischemic Stroke: Results of the VIPS Study. Circulation 2016;133:732-41.

46. Fullerton HJ, Wintermark M, Hills NK, Dowling MM, Tan M, Rafay MF, Elkind MSV, Barkovich J, deVeber GA, VIPS Investigators Risk of recurrent arterial ischemic stroke in childhood: A prospective international study.

Cite this article as: Bertamino M, Signa S, Vagelli G, Caorsi R, Zanetti A, Volpi S, Losurdo G, Amico G, Dodi I, Prato G, Ronchetti AB, Di Rocco M, Nagel M, Severino M. An atypical case of post-varicella stroke in a child presenting with hemichorea followed by late-onset inflammatory focal cerebral arteriopathy. Quant Imaging Med Surg 2021;11(1):463-471. doi: 10.21037/qims20-628
Stroke 2016;47:53-9.

47. Galea SA, Sweet A, Beninger P, Steinberg SP, Larussa PS, Gershon AA, Sharrar RG. The Safety Profile of Varicella Vaccine: A 10-Year Review. J Infect Dis 2008;197:S165-9.

48. Chaves SS, Haber P, Walton K, Robert P Wise, Hector S Izurieta, D Scott Schmid, Jane F Seward. Safety of Varicella Vaccine after Licensure in the United States: Experience from Reports to the Vaccine Adverse Event Reporting System, 1995-2005. J Infect Dis 2008;197:S170-7.

49. Donahue JG, Kieke BA, Yih WK, Berger NR, McCauley JS, Baggs J, Zangwill KM, Baxter R, Eriksen EM, Glanz JM, Hambidge SJ, Klein NP, Lewis EM, Marcy SM, Naleway AL, Nordin JD, Ray P, Belongia EA; Vaccine Safety DataLink Team. Varicella vaccination and ischemic stroke in children: is there an association? Pediatrics 2009;123:e228-34.

50. English SW, Carabenciov ID, Lehman VT, Petty GW, Scharf EL. Zoster vasculopathy surveillance using intracranial vessel wall imaging. Neurol Clin Pract 2019;9:462-4. 